\title{
Multistate Outbreak of Listeriosis Associated with Packaged Leafy Green Salads, United States and Canada, 2015-2016
}

\author{
Julie L. Self, Amanda Conrad, Steven Stroika, Alikeh Jackson, Laura Whitlock, Kelly A. Jackson, \\ Jennifer Beal, Allison Wellman, Marianne K. Fatica, Sally Bidol, Paula Pennell Huth, Meghan Hamel, \\ Kristyn Franklin, Lorelee Tschetter, Christine Kopko, Penelope Kirsch, Matthew E. Wise, Colin Basler
}

We investigated an outbreak of listeriosis detected by whole-genome multilocus sequence typing and associated with packaged leafy green salads. Nineteen cases were identified in the United States during July 5, 2015-January 31,2016 ; isolates from case-patients were closely related (median difference 3 alleles, range 0-16 alleles). Of 16 case-patients interviewed, all reported salad consumption. Of 9 case-patients who recalled brand information, all reported brands processed at a common US facility. The Public Health Agency of Canada simultaneously investigated 14 cases of listeriosis associated with this outbreak. Isolates from the processing facility, packaged leafy green salads, and 9 case-patients from Canada were closely related to US clinical isolates (median difference 3 alleles, range 0-16 alleles). This investigation led to a recall of packaged leafy green salads made at the processing facility. Additional research is needed to identify best practices and effective policies to reduce the likelihood of Listeria monocytogenes contamination of fresh produce.

Tnvasive Listeria monocytogenes infections (listeriosis) 1 are the third leading cause of death from foodborne illness in the United States and cause an estimated 1,500 infections, 1,400 hospitalizations, and 250 deaths each year (1). Although incidence of listeriosis is lower than

Author affiliations: Centers for Disease Control and Prevention, Atlanta, Georgia, USA (J.L. Self, A. Conrad, S. Stroika,

L. Whitlock, K.A. Jackson, M.E. Wise, C. Basler); US Food and Drug Administration, College Park, Maryland, USA (A. Jackson,

J. Beal, A. Wellman, M.K. Fatica); Michigan Department of Health and Human Services, Lansing, Michigan, USA (S. Bidol); New York State Department of Health, New York, New York, USA (P. Pennell Huth); Public Health Agency of Canada, Ottawa, Ontario, Canada (M. Hamel, K. Franklin, L. Tschetter); Canadian Food Inspection Agency, Ottawa (C. Kopko, P. Kirsch)

DOI: https://doi.org/10.3201/eid2507.180761 for many foodborne illnesses, it often results in severe illnesses, including sepsis and meningitis, and is associated with a high case-fatality rate and fetal loss in pregnant women (2-4). Populations at highest risk for invasive listeriosis include elderly persons, immunocompromised persons, and pregnant women and their newborns (5). Listeriosis can have a long incubation period (median 11 days, range 0-70 days) between exposure and symptom onset $(5,6)$.

L. monocytogenes was first recognized as a foodborne pathogen after an outbreak in Canada during 1981 that was linked to cabbage in coleslaw (7). Outbreaks of listeriosis in the United States have historically been associated with ready-to-eat delicatessen meats and dairy products, but have more recently been associated with fresh produce, including sprouts, celery, cantaloupe, stone fruit, and caramel apples $(5,8,9)$.

In October 2015, PulseNet USA (https://www.cdc. gov/pulsenet/index.html), the national molecular subtyping network for foodborne disease surveillance, identified a cluster of 8 clinical L. monocytogenes isolates from 6 states that were closely related genetically to one another by whole-genome multilocus sequence typing (wgMLST) (median difference 5 alleles, range 0-12 alleles); the Centers for Disease Control and Prevention (CDC; Atlanta, GA, USA) initiated a cluster investigation. During a weekly foodborne cluster investigation call on January 13, 2016, CDC informed the Public Health Agency of Canada (PHAC) of the cluster investigation, which had increased to include 13 cases of listeriosis. PHAC informed CDC of a cluster of 6 cases of listeriosis in Canada that had a pulsed-field gel electrophoresis (PFGE) pattern combination indistinguishable from that of the US cases. The United States and Canada conducted collaborative investigations to determine the source of the outbreak. 


\section{Methods}

\section{Investigation in the United States}

\section{Epidemiologic Investigation}

We defined a case as laboratory-confirmed invasive listeriosis in which L. monocytogenes was isolated from a normally sterile site (e.g., blood or cerebrospinal fluid) or from products of conception (e.g., placental or fetal tissue). Isolates were indistinguishable from the outbreak PFGE pattern combination and closely related genetically to the outbreak clade by wgMLST (0-16 alleles) (10). Isolation dates were July 5, 2015-January 31, 2016.

In the United States, state and local health departments attempt to interview all patients with listeriosis (or their proxies) by using the Listeria Initiative (LI) questionnaire, which collects standard clinical, laboratory, and demographic information, as well as data for food exposures in the 28 days before illness onset (11). At the time of this investigation, the LI questionnaire included questions on 44 foods considered to have higher risk for $L$. monocytogenes contamination on the basis of previous outbreaks, case-control studies, and expert opinion $(12,13)$. Questions about produce consumption were limited to melons, sprouts, fruit salad, coleslaw, and other ready-to-eat delicatessen-style salads $(11,12)$. We conducted case-case comparisons by using LI questionnaire data to identify common food exposures among patients and generate hypotheses about possible outbreak food vehicles. During cluster investigations, case-case comparisons can be used in lieu of traditional but time- and resource-intensive case-control comparisons by comparing exposures reported for cluster-associated cases with those reported for noncluster-associated (sporadic) cases $(14,15)$.

After initial LI questionnaire case-case comparisons failed to identify a possible food vehicle for the outbreak, we developed a supplemental questionnaire that was implemented on October 8, 2015, to collect information about foods previously associated with the outbreak PFGE pattern, including cheeses, leafy green salads, stone fruit, and caramel apples. On December 9, 2015, we began conducting single-interviewer, semistructured, open-ended interviews by using an iterative approach to identify potential food exposures not included in the previous questionnaires and obtain more complete details on food products, purchase locations, and brands $(16,17)$. During open-ended interviews, we asked about all foods consumed in the month before illness onset. When available, we reviewed grocery receipts, shopper card records, school and residential facility menus, and detailed diet logs to verify exposure details and purchase dates. Data were collected as part of the response to a public health emergency and did not meet the definition of research as provided by 45 Code of Federal Regulations 46.102(d).

\section{Regulatory Investigation}

The Ohio Department of Agriculture (ODA) routinely collects and tests retail foods for L. monocytogenes and other foodborne pathogens. Retail food samples can provide major clues during outbreak investigations if molecular subtyping identifies isolates as being closely related genetically to clinical isolates. US Food and Drug Administration (FDA) officials inspected and reviewed records from facilities linked to any L. monocytogenes isolated from food.

\section{Laboratory Investigation}

Clinical and food samples that yielded L. monocytogenes were subtyped by PFGE at state public health laboratories and FDA field laboratories by using AscI and ApaI restriction endonucleases according to PulseNet standardized protocols (18). We performed whole-genome sequencing (WGS) for all isolates and analyzed results in BioNumerics version 7.5 (Applied Maths, http://www.applied-maths. com) by using wgMLST and the Lyve-SET pipeline (10). Sequence data were uploaded to the National Center for Biotechnology Information database (https://www.ncbi. nlm.nih.gov) for sequencing analysis.

\section{Investigation in Canada}

In Canada, a case was defined as illness in a resident or visitor to Canada with laboratory-confirmed listeriosis and isolates having any of 3 outbreak PFGE pattern combinations and symptom onset on or after May 1,2015. The primary PFGE pattern combination in the outbreak in Canada was indistinguishable from that of the outbreak in the United States; 2 additional PFGE pattern combinations (patterns $A$ and B), were included for the outbreak in Canada. Initial interviews were completed by either the national Enhanced Listeriosis Surveillance Program questionnaire or provincial listeriosis questionnaires to gather food exposures during the 4 weeks before illness onset. After leafy green salads were identified as a suspected vehicle, a coordinated, centralized interviewing approach was used to reinterview patients (or proxies) who had isolates indistinguishable from those with the primary outbreak PFGE pattern.

The Canadian Food Inspection Agency (CFIA, Ottawa, Ontario, Canada) used a targeted retail sampling plan to obtain packaged leafy green salads made at a suspected processing facility from stores in Ontario and Nova Scotia during January 18-19, 2016. The targeted sampling plan included multiple salad varieties and manufacturer's code combinations from multiple processing lines that were processed during January 3-14.

Provincial laboratories performed PFGE typing of clinical isolates, and CFIA performed PFGE typing on food isolates. PFGE patterns were uploaded to the PulseNet Canada national database (https://www.canada. ca/en/public-health/programs/pulsenet-canada.html) for 
national designation by the National Microbiology Laboratory (Winnipeg, Manitoba, Canada). WGS was completed by the National Microbiology Laboratory, Public Health Ontario Laboratory (Toronto, Ontario, Canada), and CFIA on all Canadian clinical and food isolates by using single nucleotide polymorphisms (SNPs) with the SNVPhyl pipeline (19) and wgMLST in BioNumerics version 7.5. We compared isolates from Canada with those from the United States by using PFGE and WGS.

\section{Results}

\section{Investigation in the United States}

\section{Epidemiologic Investigation}

We identified 19 cases of listeriosis in 9 states: Connecticut (1), Indiana (1), Massachusetts (1), Michigan (4), Montana (2), New Jersey (1), New York (6), Ohio (2), and Pennsylvania (1) (Figure 1). All patient isolates were serotype $4 \mathrm{~b}$, indistinguishable by PFGE pattern combination, 7-gene sequence type (ST) 382, and closely related genetically to one another by wgMLST, differing by a median of 3 alleles (range 0-16 alleles) (20). Illness onset dates were July 5, 2015-January 31, 2016 (Figure 2). Of the 8 cases initially detected, 5 were later excluded by using this case definition because the isolates were different by $\geq 16$ alleles and had isolation dates before July 5, 2015.

All 19 patients were hospitalized; listeriosis contributed to $1(5 \%)$ death. Case-patients had a median age of 64 (range 3-83) years; 14 (74\%) were female. One case of listeriosis in a pregnant woman resulted in a preterm live birth. Meningitis developed in 1 otherwise healthy child with listeriosis (Table 1).
No exposures on the standard LI questionnaire were commonly reported by case-patients in the cluster, and case-case comparisons did not generate any potential food items. Five case-patients completed supplemental interviews, and 12 case-patients completed iterative, openended interviews. One patient refused to be reinterviewed but provided a detailed dietary log for analysis. Ultimately, data on leafy green vegetable consumption was available for $16(84 \%)$ of 19 patients; all 16 reported consuming leafy green salads, including $81 \%(13 / 16)$ reporting romaine lettuce and $71 \%(10 / 14)$ reporting spinach. Of those specifically asked, $93 \%$ (13 of 14) reported consuming packaged leafy green salads in the 28 days before illness onset. Nine case-patients recalled brand information; 2 packaged leafy green salad brands were reported that we determined came from a single processing facility in the United States (Table 2). Five case-patients were able to provide receipts or shopper card records to confirm purchase dates, locations, and brands. School or residential facility menus and invoices suggested potential exposure to leafy green salads for 2 additional case-patients who could not be interviewed.

\section{Regulatory Investigation}

On January 14, 2016, PulseNet staff analyzed sequence data from L. monocytogenes isolated from a packaged leafy green salad that was collected by ODA during routine retail sampling and found that it was closely related by wgMLST to clinical isolates from case-patients (median 3 alleles, range $0-16$ alleles). On the basis of these laboratory results, in combination with preliminary epidemiologic data suggesting a link to leafy green salads, on January 16, 2016, FDA initiated an inspection of the facility that processed the packaged leafy green salad.

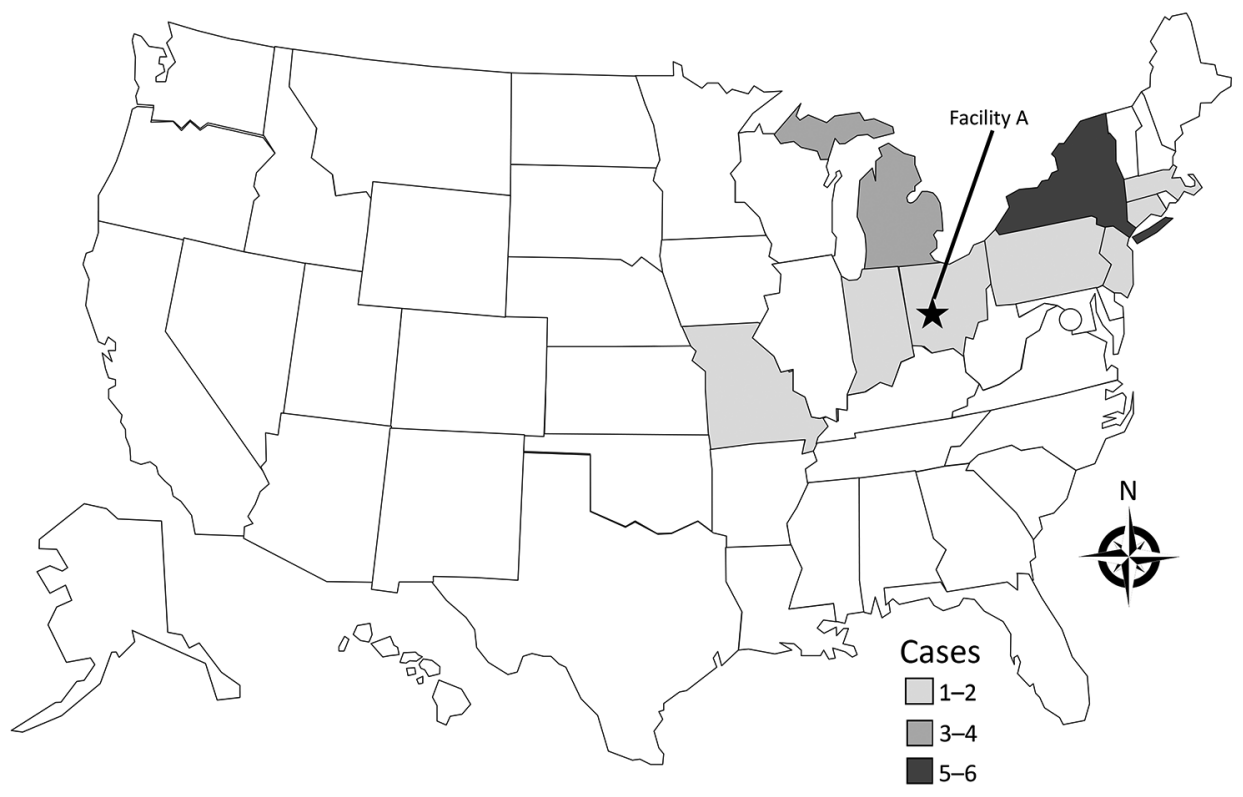

Figure 1. Outbreak-related cases of listeriosis $(n=19)$ in the United States by state of residence, July 5 , 2015-January 31, 2016. 


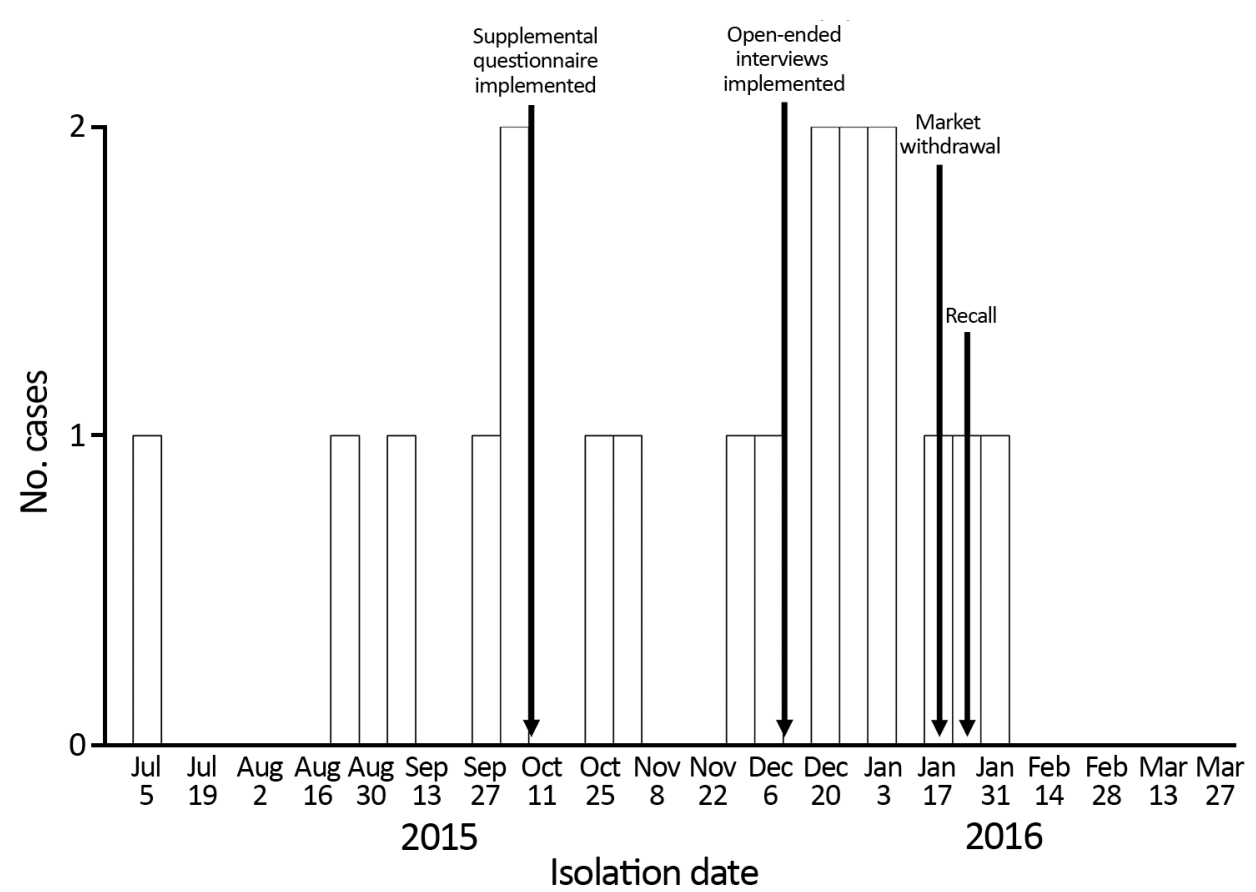

Figure 2. Timeline of Listeria monocytogenes isolation for 19 US patients during outbreak associated with packaged leafy green salads, July 5, 2015January 31, 2016.

During the facility inspection, FDA investigators observed factors that might contribute to L. monocytogenes contamination, including failure to collect environmental samples from food contact surfaces, collection of environmental samples only before production, and failure to conduct follow-up investigations beyond the standard practices after identifying Listeria spp. from environmental samples over a period of 19 months (21). Review of records indicated that the sampling program of the facility had yielded Listeria spp. 11 times during July 21, 2014January 7, 2016. Finished product, including a Caesar salad kit, and in-line samples of romaine lettuce from a production line collected by FDA from the facility on January 16, 2016, yielded L. monocytogenes (Table 3). Results from the Caesar salad kit were confirmed positive for L. monocytogenes on January 26, 2016, and those for in-line romaine lettuce were confirmed positive for L. monocytogenes on January 28. L. monocytogenes was isolated on February 9, 2016 , from an open container of packaged leafy green salad collected from the home of 1 case-patient; the salad had been processed at the same facility in the United States. Five isolates identified from the processing facility and 1 leftover product from the home of a patient were closely related by wgMLST to clinical isolates and the retail isolate (median 3 alleles, range $0-16$ alleles).

The inspection findings, the well-documented ability of Listeria species to persist in food processing/manufacturing environments, and the span of clinical cases over a period of months suggested that the source of the contamination was likely the processing/manufacturing environment, rather than a harvest site. As a result, no traceback to source farms was performed. After the FDA inspection, the processing facility implemented corrective actions.

\section{Epidemiologic Investigation in Canada}

PHAC identified 14 cases of listeriosis in 5 eastern provinces: Ontario (9), Quebec (2), New Brunswick (1), Prince Edward Island (1), and Newfoundland and Labrador (1). Illness onset dates were May 7, 2015-February 23, 2016. Ten case-patients matched the primary outbreak PFGE pattern, and 4 matched secondary PFGE pattern A. Nine $(90 \%)$ of 10 isolates from patients in Canada with the primary PFGE pattern were closely related genetically to one another $(0-5$ SNPs) and would have met the US case definition; 1 patient from Canada with the primary PFGE pattern was not closely related to the others by WGS ( $>35$ SNPs from outbreak cases). Isolates with secondary PFGE pattern A were not closely related genetically to one another and were genetically distinct from isolates with the primary PFGE pattern. All case-patients in Canada were hospitalized, and 3 (21\%) died, but it was not determined whether listeriosis contributed to the deaths.

Detailed food exposure information was collected for all 10 case-patients who had the primary outbreak PFGE pattern. Eight (80\%) reported consuming packaged leafy green salads and salad kits before illness onset. Brand information was available for 4 case-patients, and all reported or provided a purchase history that included brands made at the same US processing facility. One case-patient with secondary PFGE pattern A was interviewed by using the focused questionnaire and reported consuming coleslaw but was unable to recall the brand or product details. 
Table 1. Characteristics of 19 patients with outbreak-related listeriosis associated with packaged leafy green salads, United States, July 5, 2015-January 31, 2016*

\begin{tabular}{lc}
\hline Characteristic & Value \\
\hline Age, y, median (range) & $64(3-83)$ \\
Female sex & $14(74)$ \\
Pregnancy-associated cases $†$ & $1(5)$ \\
Hospitalization & $19(100)$ \\
Death & $1(5)$ \\
\hline Listeria monocytogenes culture site & \\
$\quad$ Blood & $14(74)$ \\
Cerebrospinal fluid & $3(16)$ \\
Placenta & $1(5)$ \\
Hip & $1(5)$ \\
\hline "Values are no. (\%) unless otherwise indicated. \\
†A pregnancy-associated case was defined as an illness in a pregnant \\
woman or infant $\leq 28$ d of age. Cases involving mother-infant pairs are \\
counted as a single case.
\end{tabular}

\section{Regulatory Investigation in Canada}

CFIA collected and tested 137 packaged leafy green salads at the retail level, representing 45 unique product type and lot code combinations processed at the same US processing facility during January 3-14, 2016. Packaged leafy green salads from 4 unique product types and lot code combinations yielded L. monocytogenes; these products included 3 varieties of packaged salad (Chopped Romaine, Caesar Salad Kit, and Colorful Coleslaw), 4 production dates (January $9-14,2016$ ), and 3 production lines (Table 3 ). Three of these varieties yielded the primary PFGE pattern that was indistinguishable from the US outbreak strain. The isolate from Colorful Coleslaw, which was distributed only in Canada, had secondary PFGE pattern B, which was not closely related by wgMLST to other clinical or food isolates. WGS showed that all food isolates from Canada that had the primary outbreak PFGE pattern were closely related to one another, to the 9 closely related clinical isolates from Canada that had the primary PFGE pattern, and to the US clinical and food isolates (range 0-16 SNPs) (20).

\section{Product Actions and Public Reporting}

On the basis of the epidemiologic data and the ODA retail surveillance sample of packaged salad that yielded the outbreak strain of L. monocytogenes, on January 21, 2016, the US processing facility voluntarily stopped production of all packaged leafy green salads because of possible L. monocytogenes contamination. On January 22, the facility issued a market withdrawal of products manufactured at that location, including 22 varieties of packaged salad sold under 6

Table 2. Consumption of leafy green salads for patients with outbreak-associated listeriosis, United States, July 5, 2015January 31, 2016

\begin{tabular}{lc}
\hline Leafy green salads consumed & $\begin{array}{c}\text { No. reported/no. } \\
\text { responses }(\%)\end{array}$ \\
\hline Any leafy green salad & $16 / 16(100)$ \\
Romaine & $13 / 16(81)$ \\
Spinach & $10 / 14(71)$ \\
Packaged salad & $13 / 14(93)$ \\
Packaged salad brand processed at facility A & $9 / 9(100)$ \\
\hline
\end{tabular}

brands in the United States and 2 brands in Canada, both organic and nonorganic brands. These products were distributed to $\geq 23$ states in the eastern and midwestern United States and eastern regions of Canada $(22,23)$. CDC, FDA, PHAC, and CFIA issued communications advising the public how to identify affected products by the manufacturing code found on the package and advised consumers and retailers to discard affected products (22-25). Consumers and retailers were also advised to thoroughly wash and sanitize anything that might have come in contact with the affected products, including refrigerator drawers and shelves, reusable grocery bags, food storage containers, countertops, and food preparation tools $(22,24,26)$. On January 27 , after receiving notification from FDA that samples from packaged leafy green salads collected during the facility inspection were confirmed positive for L. monocytogenes, the firm issued a voluntary recall of all packaged salad products made at the US processing facility with information for consumers to identify the recalled products and brands (27).

\section{Discussion}

The combination of epidemiology, retail food sampling, environmental investigation, and laboratory data confirmed packaged leafy green salads from a single processing facility in the United States as the source of this listeriosis outbreak. Observations from the facility inspection suggest that the environmental sampling plan at the facility might have limited the ability of the facility to identify L. monocytogenes contamination or harborage, which might have contributed to food contamination. Production was halted at the facility for 4 months, during which time the facility conducted testing and a root cause investigation (28). The recall and suspension of operations cost the firm an estimated \$25.5 million (28).

Several unique aspects of this investigation were essential in detecting this outbreak and identifying the food vehicle, which likely prevented additional illnesses and deaths. First, wgMLST was instrumental in distinguishing the isolates in this cluster from other L. monocytogenes isolates with the same common PFGE pattern, which has previously been isolated from multiple foods $(29,30)$. PFGE provided a standard typing scheme to facilitate interagency communication. However, the number of cases with this PFGE pattern was not above the baseline number of expected cases, and the cluster would not have been detected and could not be defined by PFGE alone. wgMLST offers greater specificity than PFGE subtyping methods and demonstrated that clinical and packaged leafy green salad isolates were closely related genetically.

Second, use of single-interviewer, open-ended iterative interviews was essential for identifying this novel vehicle. Previous foodborne outbreak investigations have identified outbreak food vehicles by using this approach after standard 
Table 3. Food isolates yielding the outbreak strain of Listeria monocytogenes, United States and Canada*

\begin{tabular}{lcc}
\hline Location of packaged salad sample collection & Packaged salad product & Collected by \\
\hline Retail store in Ohio & Field greens & Ohio Department of Agriculture \\
US processing facility & Caesar & FDA \\
US processing facility & Romaine (in-process) & FDA \\
Patient's home & Romaine & Ohio Department of Health \\
Retail store in Canada & Chopped Romaine & CFIA \\
Retail store in Canada & Caesar Salad Kit & CFIA \\
Retail store in Canada & Caesar Salad Kit & CFIA \\
Retail store in Canada & Colorful Coleslaw† & CFIA \\
\hline${ }^{*}$ CFIA, Canadian Food Inspection Agency; FDA, Food and Drug Administration. & \\
tYielded L. monocytogenes with secondary pulsed-field gel electrophoresis pattern B. & \\
\hline
\end{tabular}

interview procedures were unable to identify a likely source of infection $(16,17)$. At the time of the outbreak, the LI questionnaire did not include questions about leafy green salads, and produce questions were limited to melons, sprouts, fruit salad, coleslaw, and other ready-to-eat delicatessen-style salads. The supplemental questionnaire developed for this investigation included questions about leafy green vegetables, but data collected did not identify a specific food item or brand. In April 2016, health departments in the United States began using an updated LI questionnaire that included additional questions about produce exposures, including leafy green salads and other foods identified in recent outbreaks or recalls. In addition, institutional menus, invoices, shopper card records, and personal dietary logs can be helpful in documenting exposure details that might otherwise be unavailable and identifying new vehicles.

Third, routine retail sampling by ODA and sequencing by the state laboratory provided a molecular association between clinical isolates and a specific food product that likely would not have been made in the absence of wgMLST. Packaged leafy green salads were the leading hypothesis in the epidemiologic investigation, but the molecular relationship between the retail food isolate and clinical isolates strengthened the early epidemiologic evidence for a link to packaged leafy green salads and provided evidence needed to identify the facility and processing environment for the investigation to move forward, setting the stage for the market withdrawal and subsequent recall.

Fourth, collaboration between investigators in the United States and Canada strengthened the investigation and likely contributed to a more timely and comprehensive market withdrawal and recall. Frequent, open communication between public health and regulatory partners from both countries ensured that each party had relevant information about suspected food vehicles and laboratory findings. Extensive retail product sampling by CFIA demonstrated that the contamination of products from the implicated facility was not restricted to a single product, production line, or production day, suggesting potentially widespread contamination, and helped determine the scope of the market withdrawal and recall. WGS was also helpful in demonstrating that clinical and food isolates from Canada and the United States were closely related genetically.

Leafy green salads were one of several suspected foods identified during investigation of an outbreak of listeriosis in a hospital in Boston in 1979, and food safety research has demonstrated $L$. monocytogenes is capable of contaminating leafy green salads and ready-to-eat salads (7,31-39). However, outbreaks of listeriosis were rarely linked to produce items until outbreaks in the past decade linked to sprouts, celery, cantaloupe, stone fruit, and caramel apples. Reasons for the emergence of fresh produce as a vehicle for L. monocytogenes are unclear and might be based on increased contamination of fresh produce or improved detection. One hypothesis is that increased postharvest processing and technologies that enable increased shelf life of many products, including fresh produce, create an opportunity for proliferation of $L$. monocytogenes. Unlike many other foodborne pathogens, $L$. monocytogenes can grow at cooler temperatures (40). Studies with lettuce have demonstrated that although most foodborne pathogens on lettuce decrease in number under proper storage conditions, $L$. monocytogenes can multiply $(31,41)$. Other plausible explanations for an increase in identification of L. monocytogenes associated with produce outbreaks include improved detection of clusters because of advanced molecular techniques, such as WGS, and improved outbreak investigation techniques, such as availability of shopper card data.

Unlike most other foodborne pathogens, L. monocytogenes bacteria have the potential to grow in cold processing/ manufacturing environments and form biofilms. Therefore, additional steps might be necessary to reduce the risk for $L$. monocytogenes contamination $(31,42,43)$. For this outbreak, several factors suggest persistent contamination at the processing/manufacturing facility: distribution of illnesses over many months, facility records indicating the presence of Listeria spp. throughout a 19-month period, and CFIA retail sampling results indicating contamination on multiple days and manufacturing lines. A single case of listeriosis in the United States in 2013 was linked by wgMLST to an isolate from packaged leafy green salad produced at the same facility in the United States implicated in this investigation. The isolate from 2013 was not closely related by wgMLST (difference $>1,400$ alleles) to the isolates from this outbreak 
(44), but these findings suggest possible long-term, ongoing issues with L. monocytogenes contamination in this facility. In 2017, FDA published draft guidance for control of $L$. monocytogenes in ready-to-eat foods (45).

Vegetables and fruits are fundamental components of a healthy diet, and the US Department of Agriculture recommends that half of a person's diet be composed of fruits and vegetables (46). CDC and FDA recommend that consumers follow general food safety practices for fruits and vegetables, including leafy green salads: properly refrigerating and separating from other foods such as raw meat and seafood, discarding products that are spoiled or have been recalled, and washing thoroughly to remove surface contamination unless the packaging indicates products are prewashed or ready-to-eat $(47,48)$. However, the effectiveness of washing produce to reduce contamination varies by produce type, prior storage temperature, and washing method $(39,49,50)$. Additional research should focus on identifying best practices and effective policies to reduce the likelihood of $L$. monocytogenes contamination of fresh produce, especially as technological innovations enable increased shelf life of packaged leafy green salads and other produce.

\section{Acknowledgments}

We thank local, state, and federal partners for contributing to the Listeria Initiative (https://www.cdc.gov/listeria/surveillance/listeriainitiative.html) and the health, laboratory, and regulatory officials in the United States and Canada for contributing to this study.

\section{About the Author}

At the time of this study, Dr. Self was an Epidemic Intelligence Service officer in the Division of Foodborne, Waterborne, and Environmental Diseases, National Center for Emerging and Zoonotic Infectious Diseases, CDC, Atlanta, GA. She is currently an epidemiologist in the Division of Tuberculosis Elimination, National Center for HIV/AIDS, Viral Hepatitis, STD, and TB Prevention, CDC. Her primary research interest is the epidemiology of infectious diseases.

\section{References}

1. Scallan E, Hoekstra RM, Angulo FJ, Tauxe RV, Widdowson M-A, Roy SL, et al. Foodborne illness acquired in the United Statesmajor pathogens. Emerg Infect Dis. 2011;17:7-15. http://dx.doi. org/10.3201/eid1701.P11101

2. Silk BJ, Date KA, Jackson KA, Pouillot R, Holt KG, Graves LM, et al. Invasive listeriosis in the Foodborne Diseases Active Surveillance Network (FoodNet), 2004-2009: further targeted prevention needed for higher-risk groups. Clin Infect Dis. 2012;54 (Suppl 5):S396-404. http://dx.doi.org/10.1093/cid/cis268

3. Centers for Disease Control and Prevention (CDC). Vital signs: Listeria illnesses, deaths, and outbreaks - United States, 20092011. MMWR Morb Mortal Wkly Rep. 2013;62:448-52.

4. Listeria monocytogenes infections (listeriosis). In: Kimberlin DW, Brady MT, Jackson MA, Long SS, editors. Red Book: 2015 Report of the Committee on Infectious Diseases. 30th ed. Elk Grove Village (IL): American Academy of Pediatrics; 2015. p. 513-6.
5. Swaminathan B, Gerner-Smidt P. The epidemiology of human listeriosis. Microbes Infect. 2007;9:1236-43. http://dx.doi.org/ 10.1016/j.micinf.2007.05.011

6. Angelo KM, Jackson KA, Wong KK, Hoekstra RM, Jackson BR. Assessment of the incubation period for invasive listeriosis. Clin Infect Dis. 2016;63:1487-9. http://dx.doi.org/10.1093/cid/ciw569

7. Schlech WF III, Lavigne PM, Bortolussi RA, Allen AC, Haldane EV, Wort AJ, et al. Epidemic listeriosis: evidence for transmission by food. N Engl J Med. 1983;308:203-6. http://dx.doi.org/10.1056/NEJM198301273080407

8. Garner D, Kathariou S. Fresh produce-associated listeriosis outbreaks, sources of concern, teachable moments, and insights. J Food Prot. 2016;79:337-44. http://dx.doi.org/10.4315/0362-028X.JFP-15-387

9. Gottlieb SL, Newbern EC, Griffin PM, Graves LM, Hoekstra RM, Baker NL, et al.; Listeriosis Outbreak Working Group. Multistate outbreak of listeriosis linked to turkey deli meat and subsequent changes in US regulatory policy. Clin Infect Dis. 2006;42:29-36. http://dx.doi.org/10.1086/498113

10. Katz LS, Griswold T, Williams-Newkirk AJ, Wagner D, Petkau A, Sieffert C, et al. A Comparative analysis of the Lyve-SET phylogenomics pipeline for genomic epidemiology of foodborne pathogens. Front Microbiol. 2017;8:375. http://dx.doi.org/10.3389/ fmicb.2017.00375

11. Centers for Disease Control and Prevention. The Listeria initiative [cited 2017 Mar 24]. https://www.cdc.gov/listeria/surveillance/ listeria-initiative.html

12. Cartwright EJ, Jackson KA, Johnson SD, Graves LM, Silk BJ, Mahon BE. Listeriosis outbreaks and associated food vehicles, United States, 1998-2008. Emerg Infect Dis. 2013;19:1-9, quiz 184. http://dx.doi.org/10.3201/eid1901.120393

13. Varma JK, Samuel MC, Marcus R, Hoekstra RM, Medus C, Segler S, et al. Listeria monocytogenes infection from foods prepared in a commercial establishment: a case-control study of potential sources of sporadic illness in the United States. Clin Infect Dis. 2007;44:521-8. http://dx.doi.org/10.1086/509920

14. Mayet A. Case-case studies: an innovative tool in the field of outbreak investigation. Swiss Med Wkly. 2015;145:w14203.

15. McCollum JT, Cronquist AB, Silk BJ, Jackson KA, O'Connor KA, Cosgrove S, et al. Multistate outbreak of listeriosis associated with cantaloupe. N Engl J Med. 2013;369:944-53. http://dx.doi.org/ 10.1056/NEJMoa1215837

16. Mody RK, Meyer S, Trees E, White PL, Nguyen T, Sowadsky R, et al. Outbreak of Salmonella enterica serotype I 4,5,12:i:infections: the challenges of hypothesis generation and microwave cooking. Epidemiol Infect. 2014;142:1050-60. http://dx.doi.org/ $10.1017 / \mathrm{S} 0950268813001787$

17. Angelo KM, Conrad AR, Saupe A, Dragoo H, West N, Sorenson A, et al. Multistate outbreak of Listeria monocytogenes infections linked to whole apples used in commercially produced, prepackaged caramel apples: United States, 2014-2015. Epidemiol Infect. 2017;145:848-56. http://dx.doi.org/10.1017/S0950268816003083

18. Graves LM, Swaminathan B. PulseNet standardized protocol for subtyping Listeria monocytogenes by macrorestriction and pulsedfield gel electrophoresis. Int J Food Microbiol. 2001;65:55-62. http://dx.doi.org/10.1016/S0168-1605(00)00501-8

19. Petkau A, Mabon P, Sieffert C, Knox NC, Cabral J, Iskander M, et al. SNVPhyl: a single nucleotide variant phylogenomics pipeline for microbial genomic epidemiology. Microb Genom. 2017;3:e000116.

20. Self JL, Conrad A, Stroika S, Jackson A, Burnworth L, Beal J, et al. Notes from the field: outbreak of listeriosis associated with consumption of packaged salad - United States and Canada, 2015-2016. MMWR Morb Mortal Wkly Rep. 2016;65:879-81. http://dx.doi.org/10.15585/mmwr.mm6533a6

21. Food and Drug Administration. Letter to Coral Beach regarding FDA form 483. Food Safety News [cited 2018 Apr 5]. http://www.foodsafetynews.com/files/2016/04/Dole-483-04-25-16.pdf 
22. Food and Drug Administration. Recalls, market withdrawals, and safety alerts. Dole Fresh Vegetables announces voluntary withdrawal for salads [cited 2017 Mar 24]. https://www.fda.gov/ safety/recalls/ucm $482822 . h t m$

23. Canadian Food Inspection Agency. Food recall warning. Certain Dole brand pre-packaged chopped salads, salad blends and kits and leafy greens and certain PC Organics brand leafy greens recalled due to Listeria monocytogenes [cited 2017 Oct 13]. http://www. inspection.gc.ca/about-the-cfia/newsroom/food-recall-warnings/ complete-listing/2016-01-22c/eng/1453522915084/1453522920123

24. Centers for Disease Control and Prevention. Recall and advice to consumers, restaurants, and retailers. Multistate outbreak of listeriosis linked to packaged salads produced at Springfield, Ohio Dole processing facility [cited 2017 Mar 24]. https://www.cdc.gov/ listeria/outbreaks/bagged-salads-01-16/advice-consumers.html

25. Public Health Agency of Canada. Public health notice update: Outbreak of Listeria infections linked to packaged salad products produced at the Dole processing facility in Springfield, Ohio [cited 2017 Oct 13]. https://www.canada.ca/en/public-health/services/ public-health-notices/2016/public-health-notice-update-outbreaklisteria-infections-linked-packaged-salad-products-produced-doleprocessing-facility-springfield-ohio.html

26. Centers for Disease Control and Prevention. Multistate outbreak of listeriosis linked to packaged salads produced at Springfield, Ohio Dole processing facility [cited 2017 Mar 24]. https://www.cdc.gov/ listeria/outbreaks/bagged-salads-01-16/index.html

27. Food and Drug Administration. Recalls, market withdrawals, and safety alerts: Dole statement regarding voluntary recall of salads processed at the Springfield, Ohio facility [cited 2017 Mar 24]. https://www.fda.gov/Safety/Recalls/ucm483588.htm

28. Dole Food Company, Inc. United States Securities and Exchange Commission form S-1: registration statement, 2017 [cited 2017 May 17]. https://www.sec.gov/Archives/edgar/data/18169/ 000119312517134852/d374342ds1.htm

29. Burall LS, Grim CJ, Datta AR. A clade of Listeria monocytogenes serotype $4 \mathrm{~b}$ variant strains linked to recent listeriosis outbreaks associated with produce from a defined geographic region in the US. PLoS One. 2017;12:e0176912. http://dx.doi.org/10.1371/ journal.pone. 0176912

30. Chen Y, Luo Y, Pettengill J, Timme R, Melka D, Doyle M, et al. Singleton ST382, an emerging clonal group of Listeria monocytogenes associated with three multistate outbreaks linked to contaminated stone fruit, caramel apples and leafy green salad. J Clin Microbiol. 2017;55:931-41. http://dx.doi.org/10.1128/JCM.02140-16

31. Beuchat LR, Brackett RE. Survival and growth of Listeria monocytogenes on lettuce as influenced by shredding, chlorine treatment, modified atmosphere packaging and temperature. J Food Sci. 1990;55:755-8. http://dx.doi.org/10.1111/j.1365-2621.1990.tb05222.x

32. Beuchat LR, Adler BB, Lang MM. Efficacy of chlorine and a peroxyacetic acid sanitizer in killing Listeria monocytogenes on iceberg and Romaine lettuce using simulated commercial processing conditions. J Food Prot. 2004;67:1238-42. http://dx.doi.org/ 10.4315/0362-028X-67.6.1238

33. Lokerse RF, Maslowska-Corker KA, van de Wardt LC, Wijtzes T. Growth capacity of Listeria monocytogenes in ingredients of readyto-eat salads. Food Control. 2016;60:338-45. http://dx.doi.org/ 10.1016/j.foodcont.2015.07.041

34. Delaquis S, Stewart S, Cazaux S, Toivonen P. Survival and growth of Listeria monocytogenes and Escherichia coli O157:H7 in ready-to-eat iceberg lettuce washed in warm chlorinated water. J Food Prot. 2002;65:459-64. http://dx.doi.org/10.4315/ 0362-028X-65.3.459

35. Carrasco E, Pérez-Rodríguez F, Valero A, Garcı'a-Gimeno RM, Zurera G. Growth of Listeria monocytogenes on shredded, ready-to-eat iceberg lettuce. Food Control. 2008;19:487-94. http://dx.doi.org/10.1016/j.foodcont.2007.05.014
36. Hanning IB, Johnson MG, Ricke SC. Precut prepackaged lettuce: a risk for listeriosis? Foodborne Pathog Dis. 2008;5:731-46. http://dx.doi.org/10.1089/fpd.2008.0142

37. Crépet A, Stahl V, Carlin F. Development of a hierarchical Bayesian model to estimate the growth parameters of Listeria monocytogenes in minimally processed fresh leafy salads. Int J Food Microbiol. 2009;131:112-9. http://dx.doi.org/10.1016/ j.ijfoodmicro.2009.01.028

38. Sant'Ana AS, Landgraf M, Destro MT, Franco BD. Growth potential of Salmonella and Listeria monocytogenes in ready-to-eat lettuce and collard greens packaged under modified atmosphere and in perforated film. J Food Prot. 2013;76:888-91. http://dx.doi.org/ 10.4315/0362-028X.JFP-12-479

39. Nastou A, Rhoades J, Smirniotis P, Makri I, Kontominas M, Likotrafiti E. Efficacy of household washing treatments for the control of Listeria monocytogenes on salad vegetables. Int J Food Microbiol. 2012;159:247-53. http://dx.doi.org/10.1016/ j.ijfoodmicro.2012.09.003

40. Kornacki JL, Gurtler JB. Incidence and control of Listeria in food processing facilities. In: Ryser ET, Marth EH, editors. Listeria, listeriosis, and food safety. 3rd ed. Boca Raton (FL): CRC Press; 2007. p. 681-766 [cited 2019 May 7]. http://www.crcnetbase.com/ doi/abs/10.1201/9781420015188.ch17

41. Harris LJ, Farber JN, Beuchat LR, Parish ME, Suslow TV, Garrett EH, et al. Outbreaks associated with fresh produce: incidence, growth, and survival of pathogens in fresh and fresh-cut produce. Compr Rev Food Sci Food Saf. 2003;2(s1):78-141. http://dx.doi.org/10.1111/j.1541-4337.2003.tb00031.x

42. Walker SJ, Archer P, Banks JG. Growth of Listeria monocytogenes at refrigeration temperatures. J Appl Bacteriol. 1990;68:157-62. http://dx.doi.org/10.1111/j.1365-2672.1990.tb02561.x

43. Carpentier B, Cerf O. Review: persistence of Listeria monocytogenes in food industry equipment and premises. Int J Food Microbiol. 2011;145:1-8. http://dx.doi.org/10.1016/ j.ijfoodmicro.2011.01.005

44. Jackson KA, Stroika S, Katz LS, Beal J, Brandt E, Nadon C, et al. Use of whole genome sequencing and patient interviews to link a case of sporadic listeriosis to consumption of prepackaged lettuce. J Food Prot. 2016;79:806-9. http://dx.doi.org/10.4315/0362-028X.JFP-15-384

45. Food and Drug Administration. Draft guidance: control of Listeria monocytogenes in ready-to-eat foods: guidance for industry [cited 2018 Mar 30]. https://www.fda.gov/downloads/Food/Guidance Regulation/GuidanceDocumentsRegulatoryInformation/ CM535981.pdf

46. United States Department of Agriculture. Choose my plate [cited 2017 Mar 15]. https://www.choosemyplate.gov/MyPlate

47. Centers for Disease Control and Prevention. Fruit and vegetable safety [cited 2017 May 1]. https://www.cdc.gov/features/ foodsafetyquiz/index.html

48. United States Food and Drug Administration. Produce: selecting and serving it safely [cited 2017 May 1]. https://www.fda.gov/food/ resourcesforyou/consumers/ucm 114299

49. Doménech E, Botella S, Ferrús MA, Escriche I. The role of the consumer in the reduction of Listeria monocytogenes in lettuces by washing at home. Food Control. 2013;29:98-102. http://dx.doi.org/10.1016/j.foodcont.2012.05.074

50. Baur S, Klaiber R, Wei H, Hammes WP, Carle R. Effect of temperature and chlorination of pre-washing water on shelf-life and physiological properties of ready-to-use iceberg lettuce. Innov Food Sci Emerg Technol. 2005;6:171-82. http://dx.doi.org/ 10.1016/j.ifset.2005.02.002

Address for correspondence: Julie L. Self, Centers for Disease Control and Prevention, 1600 Clifton Rd NE, Mailstop US12-4, Atlanta, GA 30329-4027, USA; email: yxj9@cdc.gov 